\title{
El trabajo de los escultores ibéricos: un ejemplo de Porcuna (Jaén) (1)
}

\section{Iberian sculptors at work: an example from Porcuna (Jaén)}

\author{
Teresa Chapa (*) \\ Ícaro Vallejo $(* *)$ \\ María Belén $(* * *)$ \\ M. ${ }^{a}$ Isabel Martínez-Navarrete $(* * * *)$
}

\section{RESUMEN}

El estudio de las técnicas empleadas en la manufactura de las esculturas ibéricas ha recibido escasa atención por parte de los especialistas. Sin embargo, estas investigaciones han ofrecido importantes resultados en otras áreas del Mediterráneo, proporcionando conocimientos clave no sólo sobre las técnicas, talleres y estilos, sino también sobre el papel social de los escultores y de aquellos que los sostienen. Mediante el estudio de un ejemplo concreto, el grifo-león enfrentándose a la serpiente del conjunto de Porcuna, se ofrece una visión general del proceso de trabajo de la escultura. Se ha reconocido por primera vez la presencia de lo que puede ser interpretado como una marca de escultor, y se discute la función de este tipo de signos.

\begin{abstract}
The techniques employed in the manufacture of Iberian stone sculptures have received very little attention by the specialists. Nevertheless, this kind of research has provided important results in other Mediterranean areas, offering key insights not only about techniques, work-
\end{abstract}

(1) Este trabajo forma parte del proyecto "Escultura Ibérica: estudio iconográfico, tecnológico e historiográfico" del Ministerio de Ciencia e Innovación (HUM 2007-60074).

(*) Dpto. de Prehistoria. Facultad de Geografía e Historia. Universidad Complutense. Prof. Aranguren s/n. 28040 Madrid. Correo electrónico: tchapa@ghis.ucm.es

(**) Escuela de Cantería. Áncora, 31. 28045 Madrid. Correo electrónico: icaromaiterena@yahoo.es

$(* * *)$ Dpto. de Prehistoria y Arqueología. Universidad de Sevilla. María de Padilla, s/n. 41004 Sevilla. Correo electrónico: belendeamos@us.es

$(* * * *)$ Grupo de Investigación de Prehistoria Social y Económica. Instituto de Historia. CCHS-CSIC. Albasanz, 26-28. 28037 Madrid. Correo electrónico: imartinez@ih.csic.es

\author{
Bautista Ceprián $(* * * * *)$ \\ Alicia Rodero $(* * * * * *)$ \\ Juan Pereira $(* * * * * * *)$
}

shops and styles, but also about the social role of sculptors and those who support them. Through the study of a particular example, the lion-griffin confronting a snake from the sculptural group of Porcuna, we offer a general view about the way in which the sculpture was made. We have also recognized for the first time the presence of what can be interpreted as a sculptor's mark, and we discuss the purpose of these kind of signs.

Palabras clave: Cerrillo Blanco; Porcuna; Andalucía; España; Edad del Hierro; Cultura ibérica; Escultura ibérica en piedra; Cantería; Técnicas de escultura; Marcas de escultor; Firmas de escultor.

Key words: Cerrillo Blanco; Porcuna; Andalucía; Spain; Iron Age; Iberian Culture; Iberian stone sculpture; Quarrying; Sculpture Techniques; Sculptor marks; Sculptor signatures.

\section{LA ESCULTURA IBÉRICA COMO OFICIO}

El desarrollo generalizado de la escultura en piedra en el mundo ibérico es uno de los aspectos más llamativos de este período. Se trata de un oficio suntuario, desarrollado por artífices

(*****) Museo Arqueológico de Cástulo. General Echagüe, 2. 23700 Linares. Correo electrónico:

bautista.ceprian.ext@juntadeandalucia.es

$(* * * * *)$ Dpto. de Protohistoria y Colonizaciones. Museo Arqueológico Nacional. Serrano, 13. 28001 Madrid. Correo electrónico: alicia.rodero@MCU.ES

$(* * * * * * *)$ Área de Prehistoria. Facultad de Humanidades. Campus de Toledo. Universidad de Castilla-La Mancha. Plaza de Padilla, 4. 45071 Toledo.

Correo electrónico: Juan.Pereira@uclm.es

Recibido: 20-I-2009; aceptado: 16-II-2009. 
con unos conocimientos altamente especializados, que precisan además de un proceso productivo muy complejo. A pesar del interés que suscita el conocimiento de este tipo de trabajo y su relación con el grupo social que lo fomenta, la inmensa mayoría de los estudios sobre la escultura ibérica se centran en el objeto terminado, siendo los análisis iconográficos los que han recibido mayor peso por parte de la investigación. La inevitable comparación de las imágenes con otras producciones mediterráneas, unida a la sistemática falta de contexto de la mayor parte de las piezas, ha hecho que buena parte de los análisis se hayan centrado en inferir dependencias, significados y cronologías. Esta descontextualización, ya sea del emplazamiento original de la obra o de los talleres donde era trabajada, ha lastrado también los estudios sobre el proceso productivo, llevándonos a observar las piezas aisladas como objetivo central de la investigación.

Sin embargo, las esculturas en sí mismas encierran muchas claves sobre el trabajo de fabricación, y de hecho raramente dejan de presentar en su superficie las marcas de las herramientas con las que fueron talladas, especialmente en los casos en los que no llegaron a terminarse. Los estudios sobre el proceso de manufactura escultórica son frecuentes en el mundo mediterráneo (Casson 1933; Blümel 1955; Adam 1966; Palagia 2006), pero en el caso peninsular se ciñen especialmente a época romana (Nogales Basarrate 2002). Los intentos desarrollados hasta ahora para identificar las técnicas y los instrumentos de trabajo de los escultores ibéricos son todavía preliminares (Negueruela 1990-1991; Blánquez y Roldán 1994; Castelo 1995; Ramos Fernández 1996-7: 139; Izquierdo 2000: 391-394; Vives Boix 2000: 30-31). Existen también algunas determinaciones sobre el tratamiento superficial, especialmente la aplicación de pintura (Gaitán et al. 1999; Ferrero et al. 1999; Ferrero Calabuig et al. 2001; Luxán et al. 2005), pero resulta evidente que este tipo de enfoques necesitan un amplio desarrollo teórico, experimental y analítico.

El estudio global del proceso de trabajo escultórico puede enmarcarse en el tradicional concepto de "cadena operativa", que comenzaría en el momento en el que se dan las condiciones adecuadas para optar por este recurso iconográfico, analizando los diferentes componentes materiales, ideológicos y económicos. Una vez se cuenta con estos elementos se valoran las decisiones sobre el tipo de imagen, la materia prima y el em- plazamiento elegido, para pasar posteriormente a analizar todo el proceso productivo, desde la extracción de los bloques de la cantera a su transporte al lugar de trabajo, la elaboración de las esculturas y su situación final en el monumento. Ciertamente, la vida de las estatuas no termina aquí, puesto que desde el punto de vista arqueológico es fundamental conocer todos aquellos factores que inciden en su erosión, abandono, eventual destrucción y deposición final en el registro. Finalmente, la recuperación del material escultórico debe llevar a una serie de decisiones sobre su adecuada conservación y estudio, así como los sistemas idóneos de presentación al público. En definitiva, un ambicioso programa en el que no existen todavía ejemplos que recorran la trayectoria completa.

La naturaleza y posición social de los escultores ibéricos, la estructura de su trabajo, el funcionamiento de los talleres, etc., son incógnitas que es preciso desvelar. La falta de textos escritos es en este caso una notable rémora, puesto que en otros contextos, como el helénico, se conocen aspectos como los nombres de los principales artistas y su procedencia, de los clientes que encargaban las obras, e incluso detalles como las cantidades que se abonaban a los escultores (Coarelli 1980; Viviers 1992; Rolley 1994). Con esta información, aunque siempre incompleta, ha sido posible trazar un estudio del papel que la escultura cumplía en su entorno social (Duplouy 2006). Es posible que futuros hallazgos contextualizados en zonas de producción de los asentamientos, o la búsqueda generalizada de las canteras de origen, cuyo estudio no ha hecho sino empezar (Rouillard et al. 2006), vayan aportando información sobre este complejo oficio.

\section{LOS GRUPOS ESCULTÓRICOS DEL CERRILLO BLANCO}

Las excavaciones en este yacimiento, situado $1,5 \mathrm{~km}$ al norte de la actual población de Porcuna (Fig. 1), se desarrollaron entre 1975 y 1979. Los trabajos de roturación agrícola en un entorno de olivares habían dado con un buen número de esculturas que fueron adquiridas por el entonces director del Museo Provincial de Jaén, J. González Navarrete. La obtención de los permisos de actuación fue inmediata, lo que permitió recoger una gran cantidad de fragmentos escultóricos en 


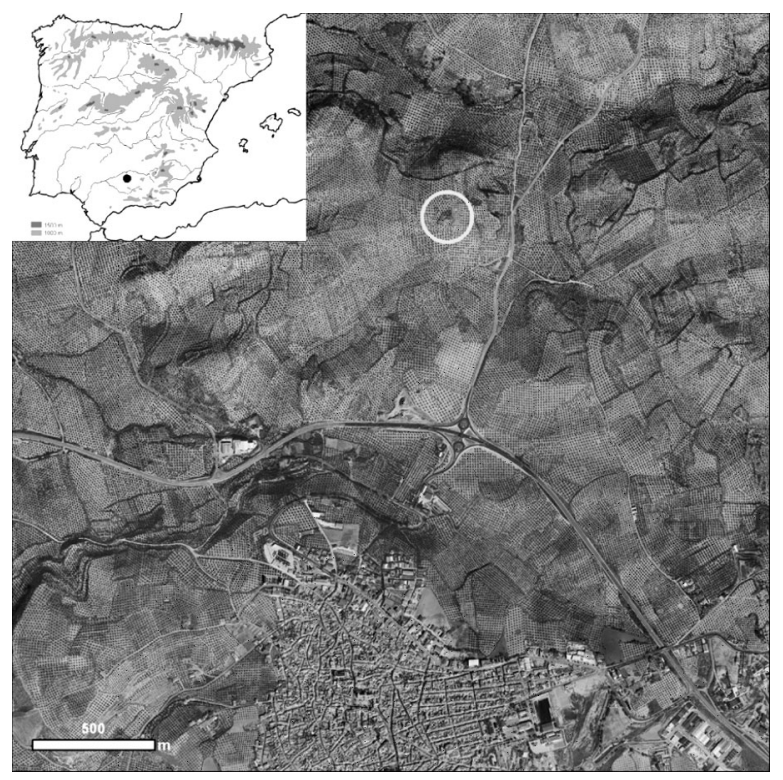

Fig. 1. Localización de Porcuna (Jaén) y del yacimiento del Cerrillo Blanco al norte de la población.

superficie e iniciar las excavaciones en junio de 1975. Definida un área de unos $80 \mathrm{~m}^{2}$, a poca profundidad se localizó una zanja cubierta por losas en cuyo interior se habían dispuesto diversas estatuas, rotas pero escasamente erosionadas. Las campañas arqueológicas se sucedieron durante los años 1976 a 1979, incorporándose en las dos últimas O. Arteaga (González Navarrete et al. 1980), que continuó desarrollando proyectos de investigación sobre la Arqueología de Porcuna durante los años siguientes (Arteaga 1999). Aunque los trabajos en el Cerrillo Blanco siguieron proporcionando ocasionalmente nuevos restos escultóricos ibéricos, la novedad más llamativa de las últimas campañas fue la localización y excavación de una necrópolis orientalizante fechada entre los siglos VII y VI a. C., y anterior, por tanto, a la zanja de las esculturas (Torrecillas 1985).

Las piezas estaban fragmentadas, aunque no todas al mismo nivel. Algunas de ellas pudieron recomponerse en gran medida, lo que permitió identificar un buen número de imágenes y proponer una serie de asociaciones significativas. Los trabajos más importantes han sido los de González Navarrete (1987), Blanco (1987, 1988), Negueruela (1990) (2), León (1998) y Olmos

(2) Los comentarios que vamos a realizar son especialmente deudores de este trabajo, que desveló muchas de las claves de la lectura iconográfica y técnica de las esculturas de Porcuna.
(2002). De ellos se deduce la existencia de varios grupos. Uno de ellos está compuesto por personajes estantes y sedentes en actitud eminentemente ritual, mientras que los otros dos se centran en los combates que mantienen dos bandos de guerreros ibéricos por un lado y enfrentamientos entre animales reales y seres míticos por otro, en los que también se cuenta el varón luchando contra un grifo, una de las piezas más llamativas del conjunto. Aunque la mayor parte de estas figuras se han tallado en bulto redondo, hay que añadir algunas representaciones en altorrelieve, como las del cazador de liebre con perro o los pugilistas, y en general muchas otras piezas fragmentadas que enriquecerían notablemente el registro del o los monumentos a los que pertenecían. La interpretación de la causa de estas fracturas ha sido muy diversa, como queda recogido por Zofío y Chapa (2005), y la cronología del conjunto suele situarse en torno a 470-420 a. C.

\section{EL ESTUDIO DE UNA PIEZA SINGULAR: EL GRIFO-LEÓN ENFRENTADO A LA SERPIENTE}

Una de las piezas que más llama la atención dentro del conjunto de Porcuna es un animal carnívoro que apoya sus garras sobre una palmeta vegetal y vuelve violentamente su cabeza hacia atrás (Lám. I). Habitualmente denominado como "leona", lo cierto es que tiene una crin que recorre longitudinalmente su cuello, rasgo impropio de estos felinos y sin embargo presente entre los grifos. El escultor mezcló voluntariamente las características de ambos, resaltando la originalidad y el carácter imaginario de esta representación (Olmos 2004: 32). La concepción de la obra deja entrever una voluntad expresa de representar una acción. Estamos ante el relato de lo instantáneo a través del movimiento, de forma que describir esta pieza exige narrar, reconocer una acción que se resume en un instante de violencia, con toda la rapidez y la fiereza que son capaces de mostrar los animales.

Por desgracia la parte posterior de la figura se ha perdido, pero la zona delantera nos permite deducir cómo sería la representación completa. De la palmeta surge el cuerpo de una serpiente que se enrosca en el cuerpo del león-grifo, y que sin duda le ataca, provocando como reacción el giro violento de la cabeza y la amenaza de su boca 



Lám. I. Escultura del grifo-león del Cerrillo Blanco (Porcuna, Jaén). A: Lado izquierdo; B: Lado derecho. Foto: Museo de Jaén.

abierta. No es una acción injustificada. Aunque no se conserva la cabeza de la serpiente, quedan los rastros del daño que inflinge a su contrincante. En el cuerpo y en la cara del león-grifo se aprecian unas marcas formadas por una puntuación de la que surge un surco horizontal (Lám. II). Tanto su forma como el hecho de que siempre se presenten pareadas permiten interpretarlas como la huella que han dejado los colmillos de la serpiente en su ataque al grifo. La mordedura apenas puede penetrar la gruesa piel del felino, pero una línea en ángulo recto marcada sobre su omóplato, en un área anterior a la disposición de estos surcos puede considerarse como el estiramiento de la piel que no llega a abrirse, al contrario de lo que sucede en el ataque de los carnívoros a los herbívoros en este mismo conjunto escultórico. No es extraño, por tanto, que el leóngrifo se revuelva con furia, aportando esa sensación de movimiento extremo.

La figura, que hoy tiene $56 \mathrm{~cm}$ de longitud, $81,5 \mathrm{~cm}$ de alto y $40 \mathrm{~cm}$ de ancho, necesitaría en el momento de su labra, y calculando lo que le falta por pérdida, un bloque inicial mínimo de $90 \mathrm{~cm}$ de longitud, $120 \mathrm{~cm}$ de altura y $45 \mathrm{~cm}$ de ancho. La piedra es una "calcarenita muy rica en globigerinas compuesta fundamentalmente de calcita, un poco de cuarzo y trazas de filosilicatos" (Espinosa Gaitán, s.a., recogido en García Martínez y Pérez-Guerra 2006: 425). Aunque se da por hecho que la cantera de procedencia es la de Santiago de Calatrava, situada a 18,5 km del Cerrillo Blanco, lo cierto es que todavía no se cuenta con procedimientos analíticos que confirmen esta atribución de forma irrefutable.

El escultor tuvo que controlar el bloque en cantera, ya que sólo de esa forma se aseguraba que no tuviera ningún defecto o grieta -"pelo", en términos de cantería-, que arruinara la pieza una vez avanzado su trabajo de talla. Dado que estos bloques no serían totalmente regulares, es probable que se eligiera uno que en cierta forma permitiese ajustar la figura que se deseaba realizar. Si tomamos como ejemplo otras formas de trabajo en el Mediterráneo, es probable que hubiera una labor de desbaste en la misma cantera. Teniendo en cuenta el peso específico de la caliza, el bloque inicial tendría algo más de $1.000 \mathrm{~kg}$, y desbastarlo en origen aligeraría razonablemente la pieza para su transporte. Este sistema se ha documentado en las canteras de El Ferriol (Alicante), donde ha llegado a encontrarse algún esbozo desechado al pie de la explotación (Gagnaison et al. 2007).

El artista ha dado una extraordinaria importancia a la cabeza del león-grifo, que parece algo desproporcionada respecto al cuerpo, un recurso que atrae la atención del espectador hacia la parte superior de la escultura, en donde se escenificaría el enfrentamiento entre los dos animales. En el trabajo final no se aprecian marcas de puntero, lo 

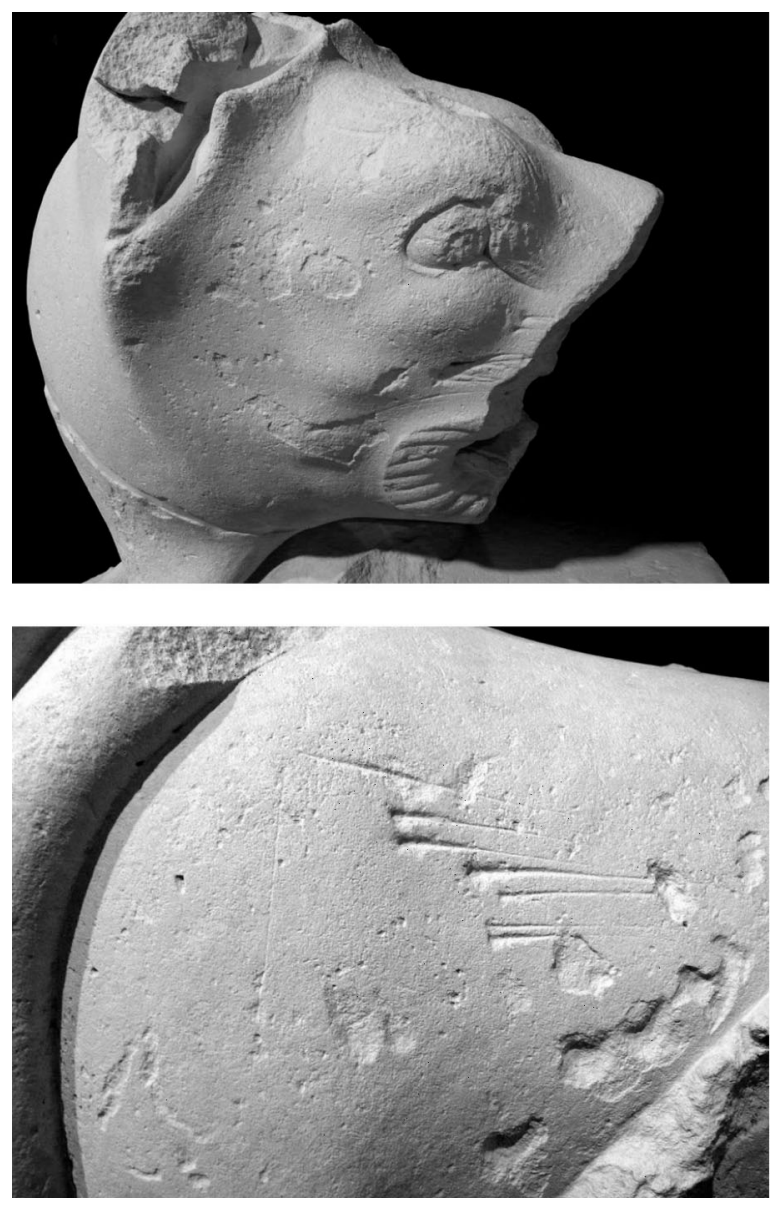

Lám. II. Incisiones simulando las mordeduras de la serpiente sobre la escultura del grifo-león del Cerrillo Blanco (Porcuna, Jaén). Foto: Museo de Jaén.

que no impide que esta herramienta fuera empleada para el desbaste inicial. En todo caso, y dadas las características de la piedra, el proceso pudo realizarse por completo con cinceles de diversos anchos, de los que quedan evidencias claras en algunas zonas que no serían fácilmente visibles, como el contacto entre la palmeta y el cuerpo del león-grifo, donde se aprecia un cincel de poco más de $1 \mathrm{~cm}$ de filo (Lám. III). Esta escultura no ha conservado su basa, pero en otros ejemplos del conjunto es aquí donde se aprecian mejor las huellas, siempre de cincel, y de diversos anchos, sobre todo de $2 \mathrm{~cm}$. Es de suponer, por tanto, que los escultores tuvieran herramientas de distintos tamaños, entre las que predomina el cincel. En el conjunto de Porcuna se documenta, además, una pieza de perfil curvo, de tipo mediacaña, que permite transmitir mejor los volú-

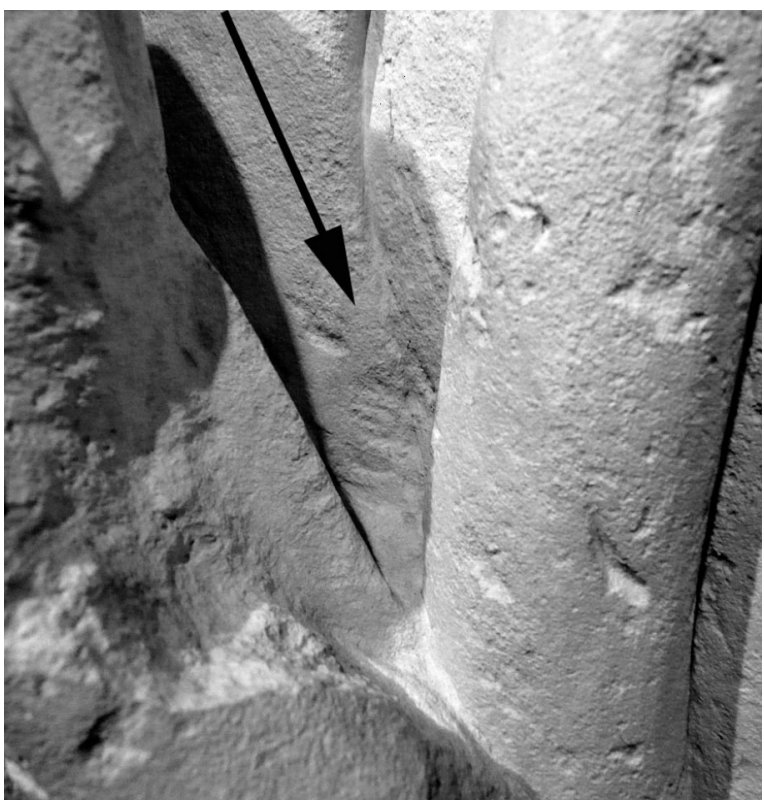

Lám. III. Localización de las marcas de cincel entre el brazo, el cuerpo y la palmeta de la escultura del grifo-león del Cerrillo Blanco (Porcuna, Jaén). Foto: Museo de Jaén.

menes, algo fundamental en el trabajo de este extraordinario escultor. Otros recursos se advierten en el trabajo de las esculturas, como el empleo de la regla para marcar con líneas finas puntos de control o representaciones concretas. En este caso, el rectángulo que precede a las incisiones de los colmillos de la serpiente. Si resulta difícil que se conserven las herramientas metálicas, todavía es más improbable la recuperación de elementos que se hicieron seguramente en materia orgánica, como la madera o el cuero, y que sin embargo forman parte inherente a este oficio.

La obra nos presenta el movimiento reptante de la serpiente como algo vivo, que recoge los pétalos de la palmeta y hace girar la cabeza al grifo plegando su cuello. Aparentemente el trabajo, que comenzaría desde arriba por la cabeza del grifo, llegaría a alcanzar las patas y los perfiles de la palmeta, cuyo recogimiento podría explicarse también como un recurso para afrontar que el bloque de piedra fuera ligeramente insuficiente. La palmeta nos muestra el detallismo expresivo del escultor, que presenta el roleo en el que se apoyan las garras del felino como materia desigualmente enrollada, girando en relieve por el lado izquierdo y mediante incisión en el lado derecho, como si hiciera sobresalir la materia por el primero de los lados (Lám. IV). El grifo no clava 

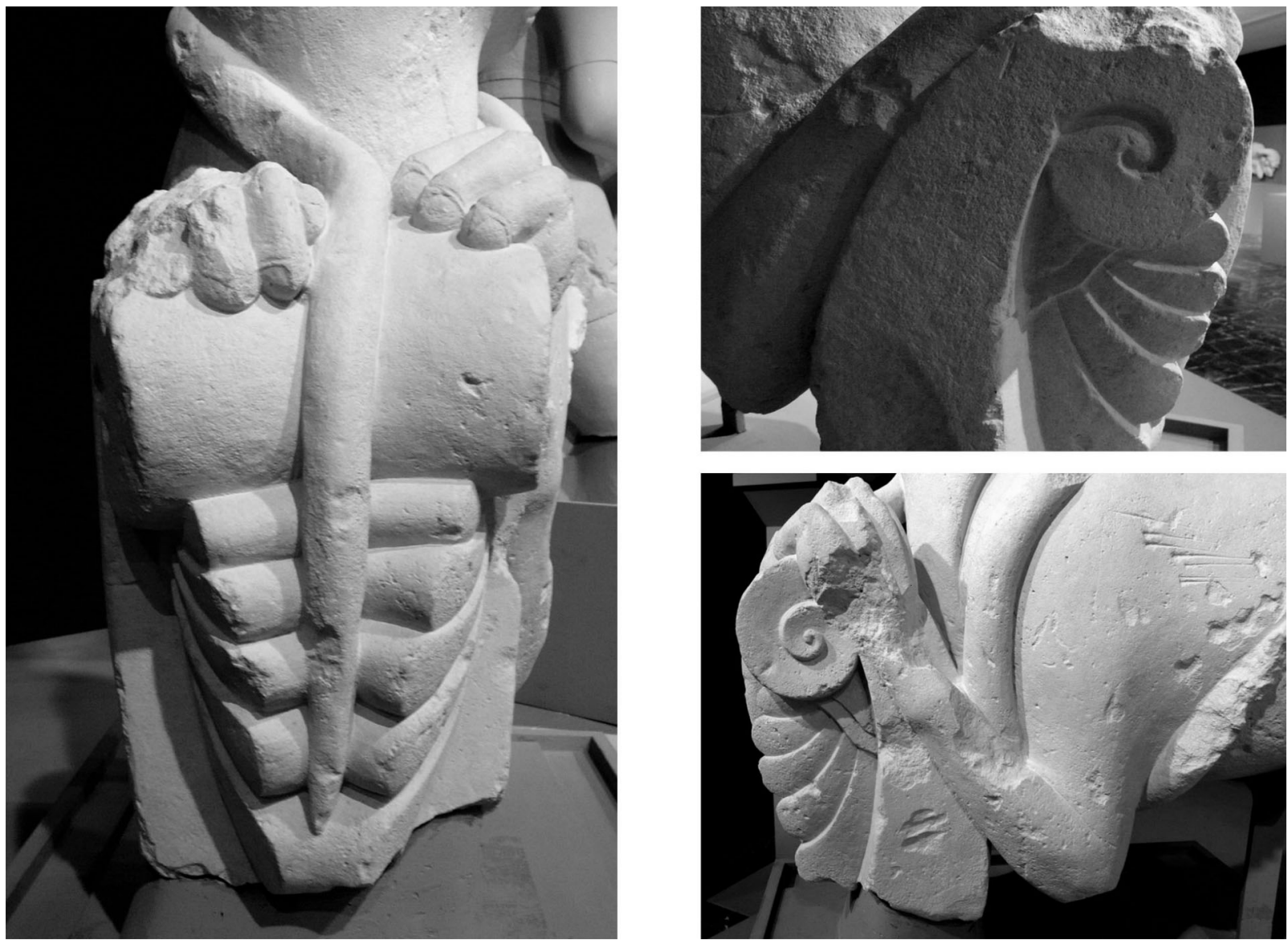

Lám. IV. Palmeta de la escultura del grifo-león del Cerrillo Blanco (Porcuna, Jaén). Obsérvense las distintas fórmulas empleadas para representar el roleo por cada lado. Foto: Museo de Jaén.

en ella sus afiladas uñas, sino que se apoya, como si estuviera a punto de saltar para intentar ponerse de cara a su contrincante.

Al llegar a este punto podría abrirse ya ligeramente el hueco entre las patas y bajo el vientre, que no llegaría a completarse hasta el final de la obra, con la escultura seguramente apoyada en una cama de arena que amortiguase unos golpes que pondrían en peligro la integridad de la pieza. El escultor pasaría entonces a dibujar los detalles de la crinera, la boca, las cejas y hocico, los ojos, etc., marcando cuidadosamente los volúmenes de cada zona. Finalmente se procedería al pulido superficial de toda la pieza, empleando productos abrasivos adecuados que todavía no han podido documentarse. La zona pulimentada muestra algunos desconchones superficiales, especialmente en la zona de la cara, que pudieron producirse en la fase de abandono, pero que no son fruto de los golpes intencionales con los que la pieza se ha roto.

Se ha señalado muchas veces la posibilidad de que esta y otras piezas estuvieran pintadas. Este hecho, que parece evidente en el caso de los carneros que rodean a un personaje en pie, no queda claro en el caso del león-grifo. Si bien hay indudables restos de colorante rojo en puntos de su superficie, lo cierto es que en parte de las zonas fracturadas también hay indicios de este color, y la propia piedra contiene pequeñas partículas rojizas que en ciertas condiciones podrían manchar su entorno inmediato. Además, no hay que olvidar la práctica habitual entre los escultores de cubrir con colorante -almagre, hojas verdes- la zona a trabajar, de forma que sea más fácil definir mediante incisiones los puntos exactos que se desea labrar. El propio proceso de trabajo borrará el color. Aunque éste no parece ser el caso que nos 
ocupa, queda para ulteriores análisis la determinación de si la escultura llegó a recibir un tratamiento de color superficial.

Como ocurre en el caso del lobo atacando al cordero (Negueruela 1990: 259; León 1998: 83), esta figura, a pesar de ser exenta, parece presentar un lado preferente de visión, que debió ser el izquierdo. Esto parece lo más probable si observamos el desarrollo del cuerpo de la serpiente por este lado, el juego más rico del cuello del grifo o de la garra sobre el roleo de la palmeta, así como los resultados de la agresión de la serpiente, localizados todos ellos en la parte derecha. Los ojos ovalados con el lagrimal alargado mediante un profundo surco son una marca de taller, ya que aunque presenten diferencias en la talla de los párpados o de las pupilas, siguen siempre el mismo diseño básico (Lám. V). Casi sin excepción van unidos en todos los animales a una zona ocular prominente, alargando el propio hueso del pómulo, y resaltando las arrugas superciliares que se marcan mediante surcos curvos paralelos.

\section{UNA POSIBLE MARCA DE ESCULTOR O DE TALLER}

Hasta el momento, no conocemos el nombre de ningún escultor ibérico. Ni la escritura fue empleada con asiduidad en la sociedad ibérica en ge-

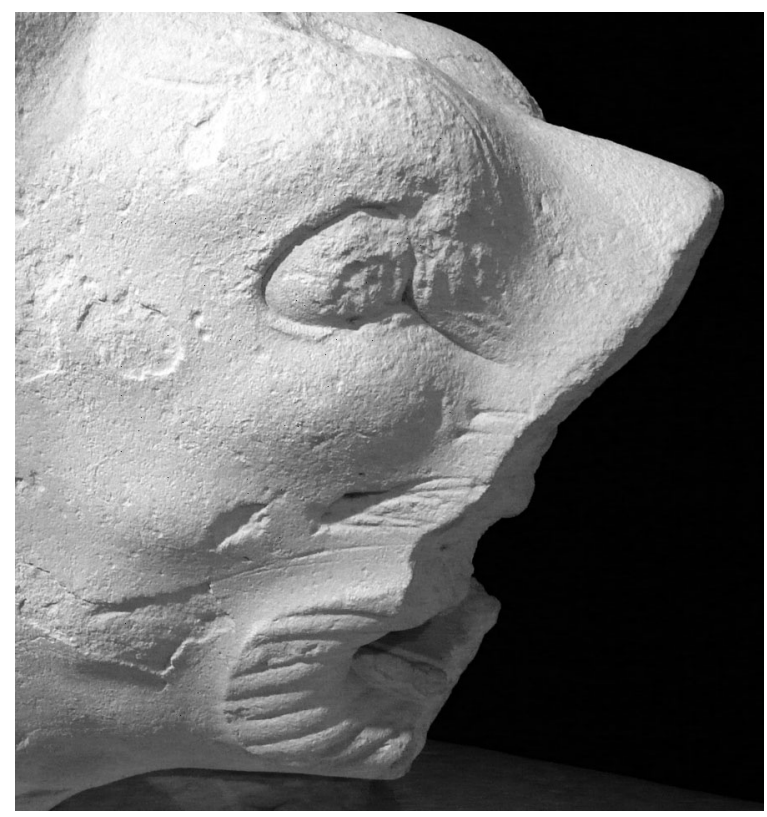

Lám. V. Detalle del ojo del grifo-león del Cerrillo Blanco (Porcuna, Jaén). Foto: Museo de Jaén. neral, ni los escultores o lapicidas la utilizaron para grabar profundamente sus nombres o los de sus clientes en sus obras, como ocurre en otros contextos mediterráneos (Siebert 1978). Las esculturas permanecen por tanto en el anonimato a los ojos de los investigadores, si bien para sus contemporáneos, los artífices de estos monumentos y los jefes de taller serían lo suficientemente conocidos como para no necesitar en gran medida esta práctica poco usual. Ello nos mueve a preguntarnos por el sentido de una marca muy tenue, pero perfectamente visible con luz rasante, que consiste en un triple rombo incompleto, de lados ligeramente curvos. Se sitúa sobre el cuello del grifo-león, y sus líneas, muy finas, fueron realizadas con la obra terminada y desde luego con anterioridad al proceso de fractura y deterioro de la pieza, puesto que algunos de los golpes recibidos afectan claramente a estos trazos (Lám. VI).

Es significativo que hasta el momento no se hubiera reparado en esta marca, a pesar de las manipulaciones y procesos de restauración y limpieza a los que ha sido sometida la figura. Indica hasta qué punto pasan desapercibidos detalles que no son activamente buscados por la investigación, y los parámetros desde la que ésta se ha enfocado no han favorecido la detección de estos signos. Sólo la presencia de un especialista como es Francisco Aguilera, cantero y escultor de Porcuna con una larga tradición familiar a sus espaldas, pudo localizar sin mayor esfuerzo estas señales, que se aprecian en varias de las esculturas actualmente expuestas en el Museo de Jaén. Entre ellas, el lobo atacando a un cordero o el cazador de liebre con perro, que presenta una marca igualmente romboidal (3).

Lo cierto es que el conjunto de Porcuna había proporcionado ya una posible inscripción ibérica asociada a un fragmento escultórico. Se trata del corvejón de un caballo en el que se ha labrado toscamente un rostro humano junto al que aparece un recuadro que enmarca una inscripción (Lám. VII). Untermann (1990: 658-659) reconoció en ella un antropónimo escrito en alfabeto ibérico meridional, proponiendo como hipótesis

(3) En el informe sin fecha realizado por la empresa T.R.P. (Taller de Restauración del Patrimonio, S.L.) para la Junta de Andalucía, una copia del cual se conserva en el Museo de Jaén, se detecta la señal grabada sobre el perro, sin que ello haya tenido repercusiones en la bibliografía ulterior. Nuestro equipo ha preparado un trabajo de conjunto sobre las diferentes marcas localizadas que será publicado en la revista Antiquity 83, 321, septiembre 2009 . 

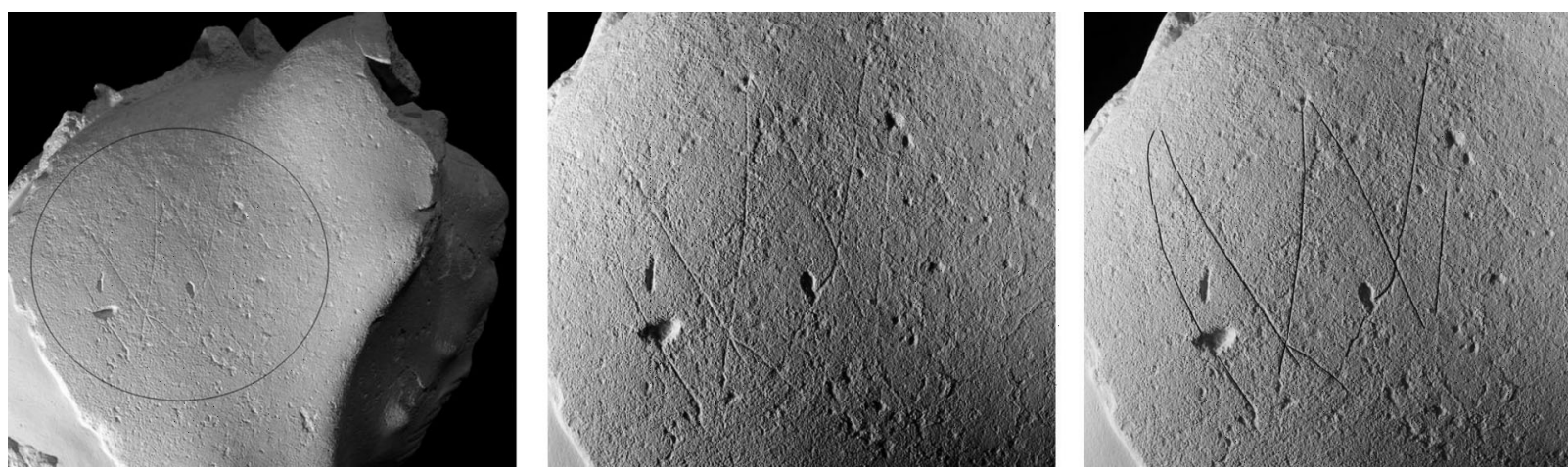

Lám. VI. Marca romboidal incisa sobre la parte trasera del cuello del grifo-león del Cerrillo Blanco (Porcuna, Jaén). Foto: Museo de Jaén.

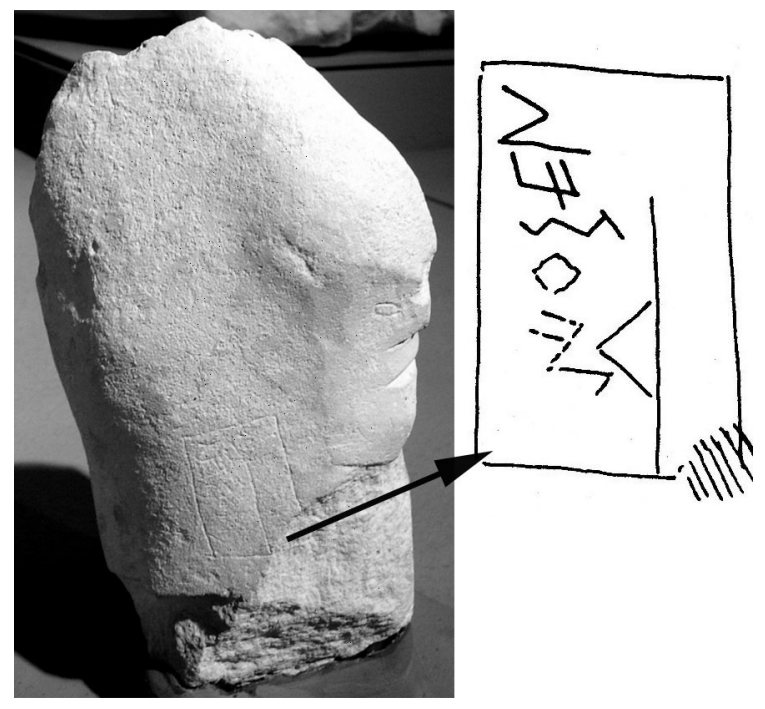

Lám. VII. Posible corvejón de caballo con representación de rostro humano muy tosco e inscripción ibérica del Cerrillo Blanco (Porcuna, Jaén). Foto: Museo de Jaén. Transcripción de Untermann (1990: 659).

que se tratara del nombre del escultor. Sin embargo, de Hoz (1995: 168), tras un examen detenido de la pieza, no consiguió determinar la lengua a la que corresponde la inscripción, dudando además de que fuera contemporánea a la fabricación de la obra. El rostro humano, similar a los que se observan en los exvotos de los santuarios ibéricos tardíos, y el hecho de que las inscripciones ibéricas no se generalicen hasta el siglo III a.C. abre la posibilidad de que estemos ante la reutilización de una pieza rota. En todo caso, la falta de datos de contexto debe mantenernos por ahora en el terreno de las hipótesis.
Como se acaba de decir, el empleo de la escritura no se hace frecuente en el mundo ibérico hasta un momento tardío, y sólo en el siglo III a.C. aparece vinculado a la iconografía, especialmente en manifestaciones cerámicas como las de San Miguel de Liria (Bonet 1995: 451-464). Sin embargo, las marcas y grafitos, correspondientes o no a letras conocidas, aparecen de forma abundante sobre muy diversos soportes (Mata y Soria 1997; Flores et al. 1999; Hoz 2002, con bibliografía) y desde fechas muy antiguas (Mederos y Ruiz 2001; Hoz 2007). En general estas marcas van asociadas a la identificación del fabricante, la materia envasada, el emisor, el receptor o el propietario final, así como a posibles cantidades de contenido o de valor. Algunas piezas importadas, como la copa de Medellín, habían llegado al territorio peninsular con alusiones rituales y fórmulas expresadas por los propios objetos (Olmos 1976). En los materiales ibéricos, es la palabra ekiar la que se interpreta como "hecho por", aunque también puede tener el sentido de "propiedad de" (Hoz 1992: 335). Los tesoros de plata con las marcas correspondientes de sus orfebres se documentan en la Península Ibérica en época tardía (Álamo 2008: 351), pero son las piezas argénteas de Abengibre, que presentan finos grabados de signos y figuras, las que nos muestran hasta qué punto la biografía de los productos de lujo es larga y acumulativa (Olmos y Perea 2004: 76).

Volviendo al grupo del león-grifo con serpiente, el signo grabado no puede identificarse con ninguna letra de los alfabetos ibéricos conocidos, incluido el greco-ibérico. Tampoco parece posible identificar en estas incisiones combinaciones de signos más sencillos. Por tanto, parece que en éste, como en el resto de grabados sobre escultu- 
ras que ya hemos citado, estamos ante marcas no epigráficas (J. de Hoz, com. pers.). El sentido que éstas pudieron tener sobre las esculturas queda vinculado al universo de la cantería y la estatuaria ibérica. Posibles marcas de cantero se aprecian sobre el monumento de Pozo Moro, interpretadas por Almagro-Gorbea (1983, Lám. 31) como indicadores de posición para los sillares del monumento, pero nada tienen que ver formalmente con el ejemplo que estudiamos. Más difíciles de interpretar son los motivos circulares levemente grabados sobre el muslo de la esfinge de Elche (Ramos Fernández y Ramos Molina 1992: Lám. XIII).

En general, y a juzgar por la extensa documentación de época medieval (Esquieu y Hartmann-Virnich 2007), los signos lapidarios pudieron tener causas y finalidades muy diversas y difíciles de detectar sin los registros escritos que los documenten. Sin embargo, las marcas observadas sobre las esculturas de Porcuna añaden a las figuras, con la máxima discreción, un componente que abre muy diversas posibilidades interpretativas. Puede leerse como la marca del propio escultor, del taller, o como un lenguaje interno que indicara la condición de la obra, su destino o la tarea pendiente, entre otras muchas posibilidades. El término adecuado podría ser el de "signatura" tal y como se define en el diccionario de la RAE: "marca o nota puesta en una cosa para distinguirla de otras".

Trabajando con estas hipótesis, podemos reconsiderar la estructura de trabajo de los escultores ibéricos, insertos en un contexto social y productivo diferente al griego, en el que la firma de los escultores y los artesanos, o los nombres de los clientes, no eran infrecuentes sobre las estatuas y otros tipos de producciones muy especializadas (Marcadé 1957; Siebert 1978; Viviers 1992). En el Próximo Oriente, donde a menudo se generaliza la afirmación de que artistas y artesanos desarrollaban un trabajo anónimo bajo mandato real (Stewart 1990: 67), se ha advertido igualmente que los artistas itinerantes contratados en grandes proyectos podían dejar su firma en lugares disimulados de la obra (Laroche 1958: 275 y 282).

En cualquier caso, queda claro que las marcas detectadas en algunas esculturas de Porcuna no fueron pensadas para tener un reconocimiento público. Como hemos podido comprobar, marcar con un puntero muy fino o con el ángulo de un cincel una piedra de este tipo no plantea ninguna dificultad, y aunque en un primer momento el trazo es bien visible, sólo con pasar la mano sobre la forma se atenúa notablemente su efecto, al penetrar de nuevo el polvo de la caliza en el interior del surco (Lám. VIII). La aplicación de pintura podría haber disimulado más el efecto, pero una revisión superficial detallada de esta figura parece descartar cualquier coloración, al menos, en esta zona. La intención de estos signos probablemente tampoco fue la de perdurar en el tiempo,
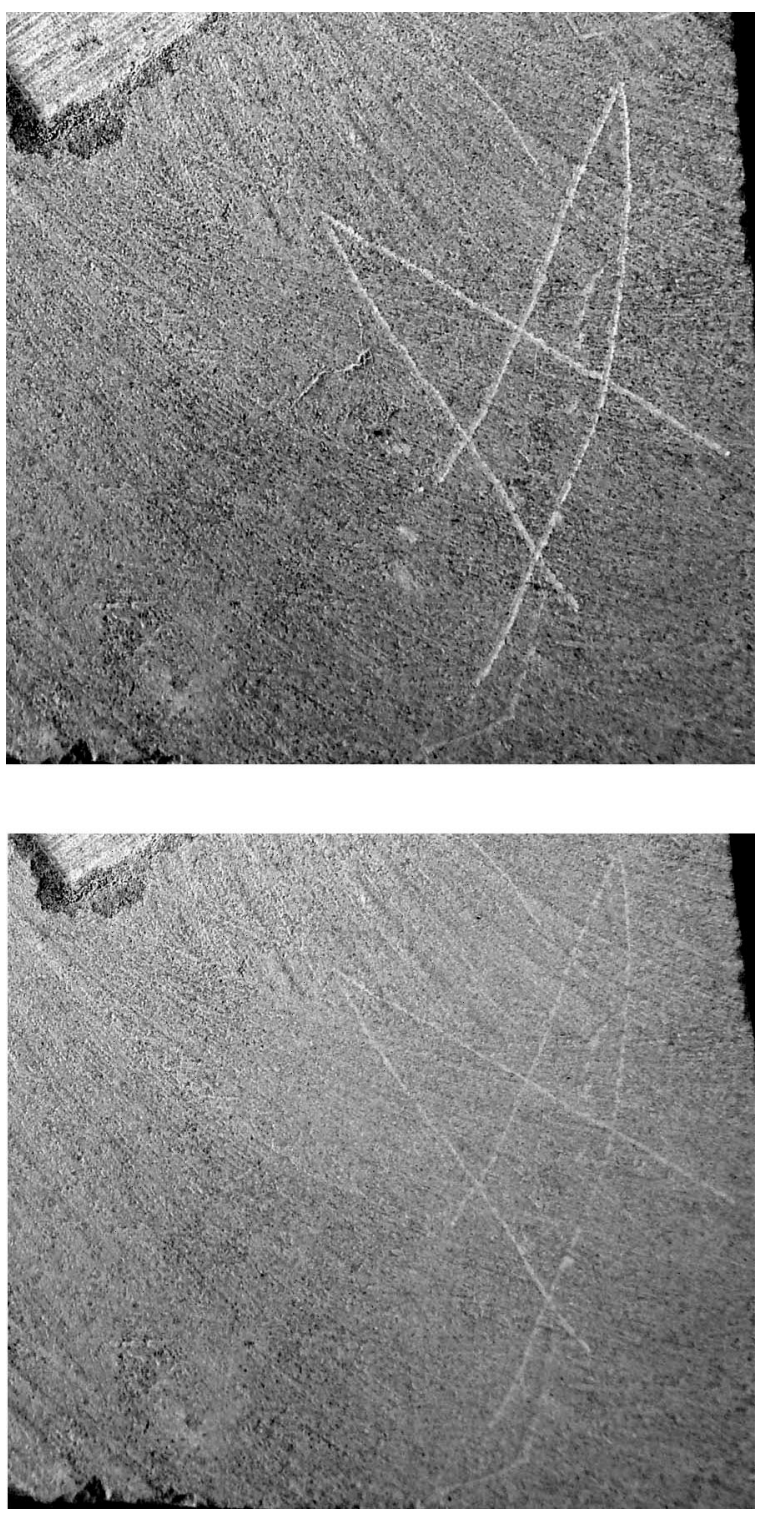

Lám. VIII. Marca experimental realizada sobre caliza con el extremo de un cincel. Arriba, recién realizada; abajo, tras pasar el dedo por encima. Foto: T. Chapa. 
puesto que la erosión superficial habría afectado fuertemente la superficie, lo que impediría la conservación de unas incisiones tan tenues.

En definitiva, parece que estamos ante una serie de marcas efímeras que tuvieron sentido en el momento de la fabricación de las obras, identificando quizás a sus autores ante sus semejantes, $o$ señalando indicaciones que se daban en el taller sobre el proceso de trabajo o el destino de las esculturas. Aunque, como se ha señalado, existen algunas otras marcas similares en el conjunto de Porcuna, una primera revisión de muchas otras piezas expuestas en la misma sala no ha dado resultados positivos, por lo que es de suponer que estamos ante comportamientos que pudieron ser excepcionales. Sin embargo, siempre queda la duda del carácter incompleto de las piezas, lo que podría sustraer del recuento nuevas evidencias. Es también motivo de reflexión que sean las esculturas que representan animales, y precisamente aquellas que alcanzan un mayor nivel de dificultad y calidad escultórica, las únicas que por el momento muestran estas señales.

Debemos al enterramiento de las piezas casi en el mismo momento de su fabricación el hecho de que en las esculturas de Porcuna puedan observarse detalles que en otros casos se han perdido. La suavidad de la superficie o la conservación de líneas de apoyo del escultor que nunca fueron borradas, indica hasta qué punto parece que las obras apenas llegaron a ser utilizadas (Ruano 1987, II: 98). Estas afortunadas circunstancias no se dan en la inmensa mayoría de las esculturas ibéricas, pero el reconocimiento de estas marcas debe llevarnos a comprobar si Porcuna fue un caso único, no sólo dentro de la Península, sino en un contexto mediterráneo más extenso.

\section{EL PROCESO FINAL DE FRACTURA Y ENTERRAMIENTO}

Según la documentación que hemos podido consultar en el Museo de Jaén (4), la pieza -sin la cabeza del grifo, cuyos datos de origen no conocemos- se recuperó en la primera campaña de excavaciones de 1975, localizándose en la cuadrícula H15, junto a un olivo y alejada de otros restos escultóricos (Lám. IX). Las imágenes muestran

(4) El trabajo en el Museo cuenta con el permiso de la Delegación Provincial de Cultura con referencia de expediente PU/13/105/08.

T. P., 66, N. ${ }^{\circ} 1$, enero-junio 2009, pp. 161-173, ISSN: 0082-5638 doi: $103989 /$ tp.2009.09018
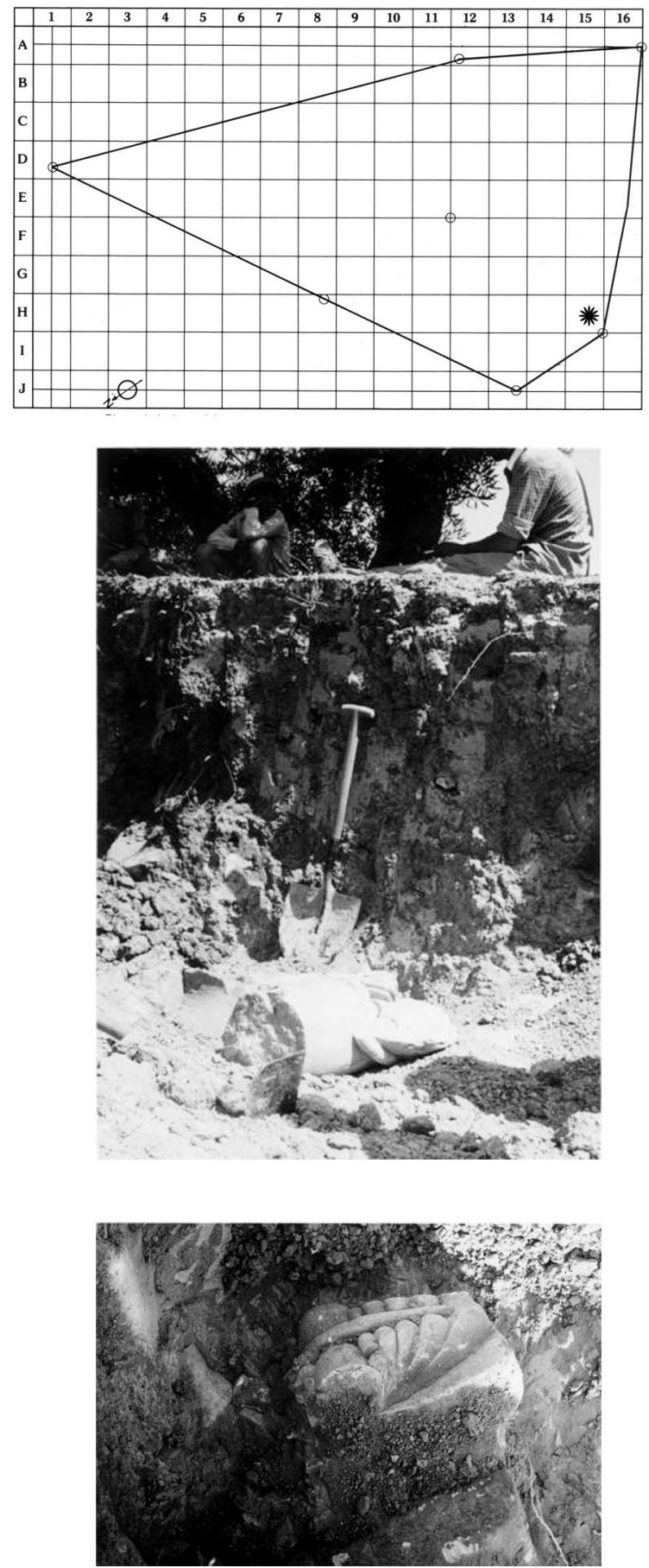

Lám. IX. Situación de la escultura del león-grifo del Cerrillo Blanco (Porcuna, Jaén) en el plano de las excavaciones de 1975. Fotografías del hallazgo realizadas por Juan González Navarrete. Documentación conservada en el Museo de Jaén. 
que la pieza estaba cubierta por tierra muy suelta, lo que sorprende teniendo en cuenta que el perfil que se muestra en una de las fotografías revela que se encontraba a más de un metro de profundidad respecto al nivel superficial. Finalmente, fue remontada en el Museo a partir de 4 fragmentos -números 415, 11, 431 y 293 del inventario-, correspondientes al cuerpo, la cabeza y lo que se conservaba de cada oreja.

La fractura que afecta al cuerpo es limpia, sin que apenas se aprecien señales junto a la zona abierta salvo una muesca en el lateral izquierdo, junto al cuerpo de la serpiente, que se encuentra muy afectado por este lado. El cuerpo del grifo tiene aquí bastantes melladuras producto de impacto de un objeto contundente, extendiéndose al brazo y garra, así como a la base del roleo del que surge la palmeta, todo lo cual reafirma la propuesta de que éste era el lado en el que se situaba preferentemente el espectador. El impacto o los impactos que arrancaron la cabeza debieron ser muy fuertes, aunque no buscaron la base del cuello sino la nuca, desde donde se desprendió toda esta parte con un corte diagonal hacia la garganta. De la fractura del morro o pico poco se puede decir, sino que una zona alterada en la espalda del felino debió ser el lugar donde terminaba la mandíbula inferior, que tendría en este caso un largo recorrido.

Contra lo que suele suceder en el conjunto de representaciones humanas, en el caso de los animales se han conservado un buen número de cabezas, aunque a menudo ha habido que reunirlas de nuevo con sus correspondientes cuerpos. Diferente situación presentan las figuras humanas, aunque las circunstancias del hallazgo abren casi ilimitadamente las posibles respuestas. En todo caso, se ha señalado repetidamente que muchas de las piezas estaban prácticamente nuevas cuando fueron enterradas. En algún caso, como el grupo del lobo atacando a un cordero, parece que incluso podríamos pensar que faltaba rematar el proceso final de trabajo en el momento en el que fue troceada.

Habitualmente no entra en nuestras valoraciones el cálculo de tiempo en los procesos de producción, algo que sin embargo es crucial a la hora de planificar y encargar una obra. Inconscientemente proyectamos hacia el pasado la inmediatez que caracteriza al uso de los recursos en nuestro mundo. La escultura realizada con sistemas tradicionales es un trabajo largo, en el que los ritmos cambian según avanza el proceso de talla. Los canteros y escultores que hemos consultado han valorado en un mínimo de tres meses el tiempo necesario para realizar la figura que estudiamos, y seguramente se emplearía un lapso mayor. Se calcula que la talla de una escultura de tamaño natural en el mundo griego duraría unos seis meses (Rolley 1994: 56), lo que nos da idea del largo proceso que fue necesario para la elaboración de los conjuntos del Cerrillo Blanco. Aunque esta producción no deba entenderse como fruto de un maestro único sino de un taller, lo que rentabilizaría la inversión de tiempo, el cálculo final de su manufactura debe contabilizarse en años más que en meses, dada la complejidad de la obra.

Se ha apuntado en repetidas ocasiones la posibilidad de que las esculturas de Porcuna formaran en realidad diversos conjuntos entregados de forma sucesiva a un lugar sacro (Olmos 2004: 21; Negueruela 1990: 312). Sin embargo, no hay diferencias apreciables en el grado erosivo de los distintos grupos a pesar de tratarse de la misma materia prima. Habrá que esperar de nuevo a estudios técnicos para analizar con suficiente detalle el grado de desgaste que presentan las piezas y formular así la posibilidad de que hubiera una producción continuada en este taller a lo largo del tiempo. En definitiva, el estudio del trabajo de los escultores aporta una nueva perspectiva al conocimiento de estas obras, de los artistas y artesanos que las realizaron y de su contexto social, y por lo tanto es una línea de importante desarrollo en un futuro inmediato. La integración de este enfoque con la lectura iconográfica supondrá, por tanto, un paso importante en la renovación de los estudios sobre la estatuaria ibérica.

\section{AGRADECIMIENTOS}

Debemos citar en primer lugar a Francisco Miguel Aguilera Casado, cantero y escultor de Porcuna, quien nos ha introducido en este complejo oficio, reparando por primera vez en las marcas presentes en algunas piezas. Francisca Hornos Mata y Margarita Sánchez Latorre, directora y conservadora respectivamente del Museo de Jaén, han puesto a disposición de nuestro equipo todos los recursos del Museo, facilitando enormemente nuestro trabajo. El profesor Javier de Hoz nos ha asesorado generosamente sobre los temas epigráficos, Ricardo Olmos ha enriquecido 
el texto con sus comentarios y Antonio Uriarte ha colaborado en la preparación de las ilustraciones. A todos ellos debemos que este trabajo haya podido culminarse.

\section{BIBLIOGRAFÍA}

Adam, S. 1966: The technique of Greek sculpture in the archaic and classical periods. British School of Archaeology, Suppl. 3. Londres.

Álamo Martínez, C. del 2008: "La colección de orfebrería de la Hispanic Society of America". En M. Bendala, C. del Álamo, S. Celestino y L. Prados (eds.): El Tesoro Arqueológico de la Hispanic Society of America. Museo Arqueológico Regional. Comunidad de Madrid. Madrid: 337-355.

Almagro-Gorbea, M. 1983: "Pozo Moro. El monumento orientalizante, su contexto socio-cultural y sus paralelos en la arquitectura funeraria ibérica". Madrider Mitteilungen 24: 177-392.

Arteaga, O. 1999: "La delimitación del territorio entre Cástulo y Obulco". En V. Salvatierra y C. Rísquez (eds.): De las sociedades agrícolas a la Hispania romana. Jornadas Históricas del Alto Guadalquivir (Quesada, 1992-1995): 95-141. Jaén.

Blanco, A. 1987: "Las esculturas de Porcuna. I. Estatuas de guerreros". Boletín de la Real Academia de la Historia CLXXXIV: 405-445.

Blanco, A. 1988: "Las esculturas de Porcuna. II. Hierofantes y cazadores; III. Animalia". Boletín de la Real Academia de la Historia CLXXXV: 1-27 y 206-234.

Blánquez Pérez, J. y Roldán Gómez, L. 1994: “Nuevas consideraciones en torno a la historiografía y tecnología de la escultura ibérica en piedra (1. ${ }^{a}$ parte)". Revista de Estudios Ibéricos 1: 61-84.

Blümel, C. 1955: Greek sculptors at work. Phaidon Press. Londres.

Bonet, H. 1995: El Tossal de Sant Miquel de Llíria. La antigua Edeta y su territorio. Servicio de Investigaciones Prehistóricas, Diputación de Valencia. Valencia.

Casson, S. 1933: The technique of early Greek sculpture. Oxford University Press. Oxford.

Castelo Ruano, R. 1995: "Técnicas y materiales constructivos en el mundo ibérico". En J.J. Blánquez Pérez (ed.): El mundo ibérico: una nueva imagen en los albores del año 2000. Junta de Comunidades de Castilla-La Mancha. Toledo: 133-143.

Coarelli, F. 1980: Artisti e Artigiani in Grecia. Guida Storica e Critica. Ed. Laterza. Roma-Bari.

Duplouy, A. 2006: Le prestige des élites. Recherches sur les modes de reconnaisance sociale en Grèce entre les $X$ et $V$ siècles avant $J$.-C. Les Belles Lettres. Paris.
Esquieu, Y. y Hartmann-Virnich, A. 2007: "Les signes lapidaires dans la construction médiévale: études de cas et probèmes de méthode". Bulletin Monumental 165, 4: 331-358, 413-414.

Ferrero, J.L.; Roldán, C.; Juanes, D. y Rovira, S. 2001: "Análisis EDXRF de pigmentos de la Dama de Baza (s. IV a.C.)". En M. a.L. Pardo Rodríguez, B.M. ${ }^{a}$ Gómez Tubío y M.A. Respaldiza (eds.): III Congreso Nacional de Arqueometría (Sevilla 1999): 109-115. Sevilla.

Ferrero Calabuig, J.L.; Roldán García, C.; Ramos Fernández, R.; Ramos Molina, A. y Ramos Molina, R. 1999: "Análisis de pigmentos en escultura polícroma ibérica de La Alcudia (Elche)". Actas del XXV Congreso Nacional de Arqueología (Valencia 1999): 540-545. Valencia.

Flores, R.; Jimeno, A.; Morales, F. y Gómez, L.M. 1999: "Marcas y fíbulas anulares de Numancia". En F. Burillo Mozota (coord.): IV Simposio sobre los Celtíberos. Economía. Homenaje a José Luis Argente Oliver (Daroca 1997): 387-394. Zaragoza.

Gagnaison, C.; Montenat, Ch.; Moratalla, J.; Rouillard, P. y Truszkowski, E. 2007: "Un esbozo de escultura ibérica en las canteras de la Dama de Elche: el busto de El Ferriol (Elche, Alicante)". En L. Abad Casal y J. Soler Díaz (eds.): Arte Ibérico en la España mediterránea (Actas del Congreso, Alicante 24-27 de octubre 2005): 141-153. Alicante.

Gaitán Espinosa, J.; Ontiveros Ortega, E.; Martín García, L.; Villegas Sánchez, R. 1999: "Estudio analítico de los materiales de la escultura ibérica denominada "El guerrero de Baza"”. En C. San Martín Montilla y M. Ramos Lizana (coords.): El guerrero de Baza. Consejería de Cultura. Junta de Andalucía: 49-56.

García Martínez, H. y Pérez-Guerra Salgado, J.J. 2006: "Restauración de las esculturas ibéricas de Cerrillo Blanco de Porcuna (Jaén)". Sautuola XII: 421- 432.

González Navarrete, J. 1987: Escultura Ibérica de Cerrillo Blanco, Porcuna, Jaén. Diputación Provincial de Jaén. Instituto de Cultura. Jaén.

González Navarrete, J.; Arteaga, O. y Unguetti, C. 1980: "La necrópolis del Cerrillo Blanco y el poblado de Los Alcores (Porcuna, Jaén)". Noticiario Arqueológico Hispánico 10: 185-217.

Hoz, J. de 1992: "Estudio epigráfico". Estudios de Arqueología Ibérica y Romana. Homenaje a Enrique Pla Ballester. Servicio de Investigaciones Prehistóricas, Serie de Trabajos Varios 89. Valencia: 330-344.

Hoz, J. de 1995: "Ensayo sobre la epigrafía griega de la Península Ibérica". Veleia 12: 151-179.

Hoz, J. de 2002: "Grafitos cerámicos griegos y púnicos en la Península prerromana". Archivo Español de Arqueología 75 (185-186): 75-91. 
Hoz, J. de 2007: “Cerámica y epigrafía paleohispánica de fecha prerromana”. Archivo Español de Arqueología 80: 29-42.

Izquierdo Peraile, I. 2000: Monumentos funerarios ibéricos: los pilares-estela. Diputación Provincial de Valencia. Servicio de Investigación Prehistórica. Serie de Trabajos Varios 98. Valencia.

Laroche, E. 1958: "Étude sur les hiérogliphes hittites". Syria 35: 252-283.

León, P. 1998: La sculpture des Ibères. l'Harmattan. Paris.

Luxán, M.P.; Prada, J.L. y Dorrego, F. 2005: “Dama de Elche: pigments, surface coating and stone of the sculpture". Materials and structures 38 (277, April): 419-424.

Marcadé, J. 1957: Recueil des signatures des sculpteurs grecs. Boccard. Paris.

Mata Parreño, C. y Soria Combadiera, L. 1997: "Marcas y epígrafes sobre contenedores de época ibérica. Marcas y epígrafes sobre contenedores de época ibérica". Archivo de Prehistoria Levantina XXII: 297-374.

Mederos Martín, A. y Ruiz Cabrero, L. 2001: "Los inicios de la escritura en la Península Ibérica. Grafitos en cerámicas del Bronce Final III y fenicias". Complutum 12: 97-112.

Negueruela, I. 1990: Los monumentos escultóricos ibéricos del Cerrillo Blanco de Porcuna (Jaén). Ministerio de Cultura. Madrid.

Negueruela, I. 1990-1991: “Aspectos de la técnica escultórica ibérica en el siglo V a.C.". Lucentum IX-X: 77-83.

Nogales Basarrate, T. (ed.) 2002: Materiales y técnicas escultóricas en Augusta Emerita y otras ciudades de Hispania. Cuadernos Emeritenses 20. Museo Nacional de Arte Romano. Mérida.

Olmos, R. 1976: "En torno al kylix de Medellín”. Habis 7: 251-264.

Olmos, R. 2002: "Los grupos escultóricos del Cerrillo Blanco de Porcuna (Jaén). Un ensayo de lectura iconográfica convergente". Archivo Español de Arqueología 75 (185-186): 107-122.

Olmos, R. 2004: "Los príncipes esculpidos de Porcuna (Jaén): una aproximación de la naturaleza y de la historia". Boletín del Instituto de Estudios Giennenses 189: 19-43.
Olmos, R. y Perea, A. 2004: “La 'vajilla' de plata de Abengibre". En R. Olmos y P. Rouillard (eds.): La vajilla ibérica en época helenística (siglos IV-III al cambio de era). Casa de Velázquez. Madrid: 63-76.

Palagia, O. (ed.) 2006: Greek Sculpture. Function, Materials and Techniques in the Archaic and Classical Periods. Cambridge University Press. Cambridge.

Ramos Fernández, R. 1996-1997: “La Dama de Elche". Arx 2-3: 139-147.

Ramos Fernández, R. y Ramos Molina, A. 1992: El monumento y el témenos ibéricos del Parque de Elche. Ajuntament d'Elx. Elche.

Rolley, C. 1994: La Sculpture Grecque. 1 Des origines au milieu du V siècle. Picard. Paris.

Rouillard, P.; Gagnaison, C.; Montenat, Ch.; Moratalla, J. y Truszkowski, E. 2006: "Au Pays de la Dame d'Elche, la carrière et l'ébauche de buste de El Ferriol (Elche, Alicante)". Académie des Inscriptions \& Belles Lettres. Comptes Rendus des Séances de l'Année 2006 (Janvier-Mars). Paris: 243-253.

Ruano, E. 1987: La escultura humana de piedra en el mundo ibérico. Tesis de la Universidad Autónoma. Madrid. 3 vols.

Siebert, G. 1978: "Signatures d'artistes, d'artisans et de fabricants dans 1'Antiquité classique". Ktema 3: 111-131.

Stewart, A. 1990: Greek Sculpture. An Exploration. Yale University Press. New Haven y Londres.

Torrecillas González, J.F. 1985: La necrópolis de época tartésica del "Cerrillo Blanco" (Porcuna, Jaén). Diputación Provincial. Jaén.

Untermann, J. 1990: Monumenta Linguarum Hispanicarum III: Die iberischen inschriften aus Spanien. Reichert. Wiesbaden. 2 vols.

Vives Boix, F. 2000: La Dama de Elche en el año 2000. Análisis tecnológico y artístico. Col. Gorgona, Ed. Tilde. Valencia.

Viviers, D. 1992: Recherches sur les ateliers de sculpteurs et la Cité d'Athènes à l'époque archaïque: Endoios, Philergos, Aristoklès. Académie royale de Belgique. Bruselas.

Zofío Fernández, S. y Chapa Brunet, T. 2005: "Enterrar el pasado: la destrucción del conjunto escultórico del Cerrillo Blanco de Porcuna (Jaén)". Verdolay 9: 95-120. 